\title{
Understanding Therapeutic Sensory Stimulation Garden (TSSG) as a Rehabilitation Garden in a Healthcare Centre
}

\author{
Noor Azlina Mohamed Khalid, Lydia Abdul Latif, Hazreena Hussein
}

\begin{abstract}
Therapeutic garden in the hospital has been known as one of the promising intervention tools to improve the psychological, cognitive, social, and physical functions of patients in the healthcare center. Large numbers of literature found on the benefit of a therapeutic garden, however, there were limited discussions related to rehabilitation among disabled patients during their hospitalization. Therefore, this study is aimed to develop a clearer understanding of a therapeutic garden used for physical rehabilitation by neurological disorder patients. Therapeutic Sensory Stimulation Garden (TSSG) was chosen as the site study and behavioral mapping technique was employed to map the pattern of space use, movement, and types of activities in the garden. From this observational study, it was discovered that three primary components were involved in defining the pattern of space use, movement and activity in TSSG during rehabilitation: people, environment and activities. Therefore, to design a hospital's garden for rehabilitation, knowing these three aspects was vital. This research demonstrates that TSSG appears to be useful as a supplementary instrument for patients with neurological disorder, particularly in their early rehabilitation intervention phases..
\end{abstract}

Keywords: Garden, hospital, observation, rehabilitation.

\section{INTRODUCTION}

The therapeutic garden in the hospital offers a getaway environment from the clinical atmosphere and promotes positive interaction between users and the green environment [1]-[4]. Based on evidence-based research, it was utilized as one of the non-pharmaceutical assessment tools [2], [5] to improve health and wellbeing in rehabilitation intervention. According to [6], rehabilitation interventions were highly recommended to be started as soon as possible when the patients have been diagnosed with neurological disorder. Dementia, epilepsy, headache disorders, multiple sclerosis, neuroinfections, Parkinson's disease, stroke and traumatic, brain injuries are included in neurological disorders. These patients needed to face with several limitations such as physical functioning limitations, cognitive impairments, behavioural problems, communication impairments, basic daily living activities and psychosocial limitations and by being in a garden, it will help to reduce the stress of patients [3], [7] and alleviate

Revised Manuscript Received on September 14, 2019.

Noor Azlina Mohamed Khalid, Center for Sustainable Urban Planning and Real Estate, Faculty of Built Environment, University Malaya, Kuala Lumpur, Malaysia; Product Design Department, School of The Arts, University Sains Malaysia, Pulau Pinang, Malaysia. (Email: azlinakhalid@gmail.com)

Lydia Abdul Latif, Department of Rehabilitation Medicine, Faculty of Medicine, University Malaya, Kuala Lumpur, Malaysia. (Email: 1ydialatif@um.edu.my)

Hazreena Hussein, Center for Sustainable Urban Planning \& Real Estate, Faculty of Built Environment, University Malaya, Kuala Lumpur, Malaysia. (Email: reenalambina@um.edu.my.) patient's emotional impact, especially of being hospitalized for an extended period of time [2], [4].

The therapeutic garden had been used for rehabilitation purposes and played a great role as a supportive environment in rehabilitation medicine [2], [7]. However, there were limited studies discussing on physical rehabilitation [7]-[9], intervention in the green environment, especially involving patient with disabilities [7], [10] and inpatient [2], [10] of rehabilitation unit [2], [3] in acute hospital. Therefore, this study aims to understand how the therapeutic garden was used for physical rehabilitation among patients with disabilities, thus providing additional insight into environment-behaviour research. By using Therapeutic Sensory Stimulation Garden (TSSG) as a site study, below research questions were addressed in achieving the study aim:

i) Which area in TSSG is being used the most and what are the contributing factors?

ii) What are the movement patterns of the users during rehabilitation sessions in TSSG?

iii) What type of activities was undertaken during rehabilitation intervention in TSSG?

\section{LITERATURE REVIEW}

\section{A Garden Malaysian Healthcare}

The relationship between gardens and hospitals as an important outdoor element is undeniable. According to [11], out of 137 government hospitals in Malaysia, there were 88 hospitals identified to be facilitated with gardens and out of it, 55 were labelled as Therapeutic Garden. However, little is known about the use of the therapeutic garden for physical rehabilitation in an acute hospital that involves patients with disabilities. Currently, in Malaysia, physical rehabilitation will take place in an indoor environment as most of the rehabilitation equipment was located in the building [1]. However, recently, it was found that UMMC offered physical rehabilitation to patients with disabilities in their TSSG [12], [13]. This scenario portrayed as a positive sign in Malaysian healthcare environment development. In conjunction with this matter, in [14] also highlighted the potential of a garden in supporting rehabilitation therapy in the healthcare center. Their research discussed in the use of a hospital's green outdoor environment (GOE) for rehabilitation among cardiovascular patients. They urged that more evidence-based studies were carried out to prove the benefits of GOE in hospitals. They suggested that future 


\section{UNDERSTANDING THERAPEUTIC SENSORY STIMULATION GARDEN (TSSG) AS A REHABILITATION GARDEN IN A HEALTHCARE CENTRE}

research should explore further the relationship between GOE and rehabilitation with other illnesses.

\section{$B$ Garden and Rehabilitation Intervention}

Recent research has proven that the garden served as an agent for recovery and rehabilitation [7], [15]; however, it was observed to be used passively [9]. According to [16], the emphasis was given more on passive interaction compared to active interaction in the garden. No doubt, psychologically, passive interaction with green environment has proven to contribute towards the relaxation of patients, participation needed to be explored further as active participation activities that involve physical rehabilitation such as exercise and movement, will typically take place in a clinical setting or indoor gym [1], [17], [18]. Anyhow, since physical environment plays an essential role in influencing patient's exercise performances [4], [17], the design of gym with glass wall or partition were used to create a positive ambiance [7], [17] and motivates patients to engage in their exercise programmed compared to the enclosed gym [17]. Nevertheless, by extending the therapeutic garden as part of a rehabilitation clinic, gym, or part of the assessment room, it incorporates the outdoor environment into the hospital setting [15]. Apart from that, it can also serve as a great mechanism to support psychology and physical-oriented rehabilitation [7].

\section{Garden, Disability and Universal Design (UD)}

Rehabilitation deals with human functioning that interacts with the larger environment, physically, socially and economically [6]. As disability will affect an individual's functioning, rehabilitation will help disabled patients to be more independent. In [19] defines rehabilitation as "Therapeutic restoration, after disease, illness, or injury, of the ability to function in a normal or near-normal manner", which explained that the aimed of rehabilitation is to support patients in improving their capabilities, both physically and psychologically. Patients will face a particular limitation in doing activities and had a specific restriction in participation due to physical functioning limitations, cognitive, and communication impairments [6]. Hence, by discussing rehabilitation intervention in a green outdoor environment, accessibility became the main concern [9], [10], especially involving a patient's physical functioning limitations. For example, patients with low physical functioning will face a huge challenge to access a garden if it is not accessible enough for a wheelchair user. For this reason, when it involves designing for people with different abilities, it is crucially important to identify their primary needs [10]. According to [20], patients that visited the outdoor environment will need to depend much on their health condition. Most of the patients that visited the outside environment in a hospital were mostly stable in health, able to walk and free from any medical equipment. Although architecture plays an essential role in supporting hospitals' comprehensive management of providing accessible facilities to all users [6], but yet, not all gardens are userfriendly and easy to access [1], [10]. Consequently, a lack of understanding of good universal design principles was one of the reasons why a garden is not user-friendly for patients but the relationship between green environment and active

with disabilities [10]. Just like any patients, physically disable patients also deserve to experience the outdoor environment during their hospitalization. Thus, understanding of universal design is vital.

\section{METHODOLOGY}

\section{A Study Area}

Therapeutic Sensory Stimulation Garden (TSSG) was selected as a case-study site. It is a rooftop garden and located on the sixth floor of Menara Selatan of Universiti Malaya Medical Centre (UMMC), Kuala Lumpur; sharing the same building with rehabilitation wards and clinics. The $1200 \mathrm{sq} / \mathrm{m}$ garden was launched in October 2014, primarily for recreational and rehabilitation activities of patients. The garden's concept is to stimulate spatial, emotional and spiritual senses together with the five basic senses (hearing, sight, touch, taste, and smell) during rehabilitation intervention [12]. It is a collaborative project between BAKTI and UMMC in increasing awareness of inclusiveness and accessibility. The application of Universal Design principles in TSSG is aimed to promote accessibility, ease of use and safety in recreational and leisure activities that suit all members of the community, including People with Disabilities (PwD). TSSG has been selected as the site of this study by considering the suitability of the study objective; which related to physical rehabilitation intervention for disable patients in the garden area. Apart from that, to the best of researcher's knowledge, it is the only garden in Malaysian acute hospitals that offers TSSG concepts in a hospital's garden [13]

\section{B Study Participants}

The selection of participants was done through convenience sampling [2] assisted by occupational therapists in charged for rehabilitation sessions. Neurological disorder patients scheduled for rehabilitation in TSSG were invited to participate with consent. Participants for Wednesday rehabilitation sessions were inpatients and neurological disorder patients. Most of them were in wheelchairs. They were adult patients, aged 18 years old and above. The participants involved both genders from a diverse ethnicity.

\section{Ethics Approval}

Ethics approval granted from UMMC Medical Research Ethics Committee (MREC ID No: 20181196875) and layout plan of TSSG was obtained from the Engineering Department through the permission permitted by UMMC Director and Head Department of Rehabilitation.

\section{Observation and Behavioral Mapping}

During the observational study on how TSSG were used during rehabilitation, therapists and patients were advised to perform their activities as usual. This study applied direct and non-participation observation. This method helps to create a better understanding of designing a physical environment among designers [2], [21]. 
In this study, behavioral mapping was applied to support the observation done in TSSG [5], [9], [20], It was primarily used to map the area use, movement, and activity pattern in a space, thus providing a deeper understanding of the relationship between the user and the environment. It is known as a prominent observational instrument applied in the person-environment study. This observational study applied direct observation in understanding how rehabilitation intervention was done in TSSG. The field observation was performed accordingly to the regular rehabilitation working day scheduled for neurological disorder patients and the observations were undertaken every Wednesday (March to May) from 9.00 am to 11.30 am. While performing direct observation, a paper form was used to locate the participant's locations, movements and activities at 10 minutes observation point [2], and mapped on the TSSG layout plan (refer Fig. 1).

TSSG layout map was divided into 11 sections to make it easier for the researcher to record the area used during rehabilitation intervention. There was three major division of zones: center $(\mathrm{C})$, left $(\mathrm{L})$, and right $(\mathrm{R})$ area. The center area was divided into three smaller sections, which were $\mathrm{C} 1$, $\mathrm{C} 2$, and $\mathrm{C} 3$. Meanwhile, the left and right areas were divided into four smaller sections, which were L1 to L4, and R1 to R4 (refer Fig. 2).

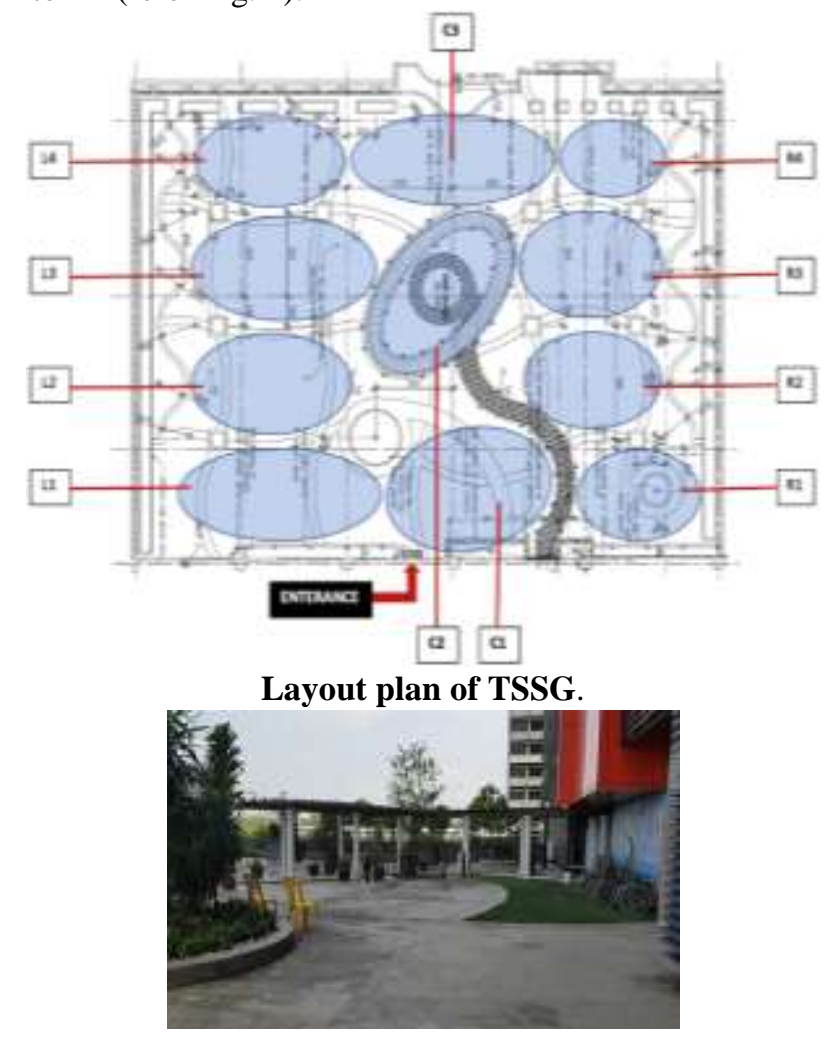

(a)

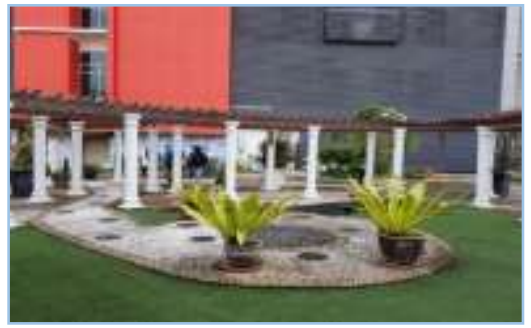

(b)

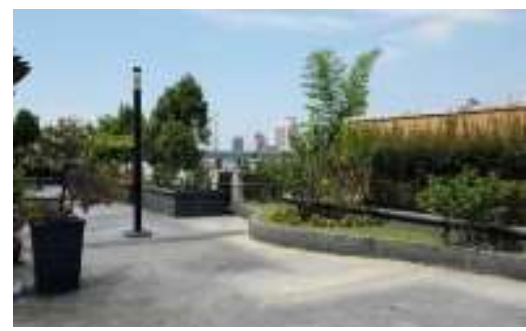

(c)

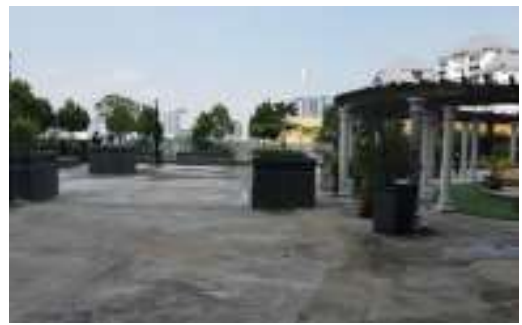

(d)

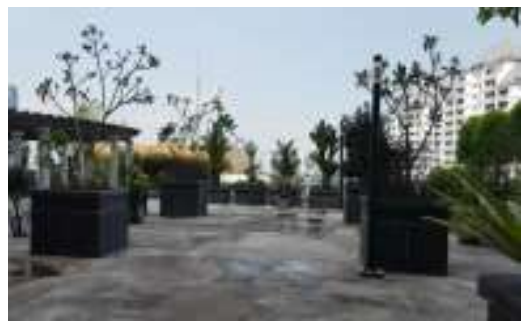

(e)

Fig. 2(a) Area C1, (b) Area C2 (c) Area C3, (d) Area L1 to L4, (e) Area R1 to R4.

\section{E Data Analysis}

This study will only highlight data related to the aim of the study, which was to observe how the garden was utilized to support rehabilitation intervention for patients with disabilities. Data were analyzed accordingly to space use pattern, participant movement pattern (mobility) and activity profile pattern. The frequency of the space used and activities that occurred in TSSG was recorded and presented descriptively [2], [20]. The data displayed helps to determine the characteristics of a rehabilitation garden used by disabled patients.

\section{RESULTS AND DISCUSSION}

\section{A Space Use Pattern}

Based on the observation, TSSG was used for group sessions and individual sessions. The group sessions were divided into two types, Group Session 1 (GS1) and Group Session 2 (GS2). Each session took place in different areas in TSSG. Referring to Fig. 2, C1 was consistently used for GS1 since it was the only area utilized for GS1 activities during the whole ten rehabilitation sessions. Meanwhile, space usage for GS2 appears to be more diversity. Five different areas were observed to be used for GS2 throughout all ten sessions in TSSG, with L1 being the most utilized space for GS2 followed by L2 and L3. Out of ten sessions, L1 was used for six rehabilitation sessions (refer Fig. 3).

Published By: 


\section{UNDERSTANDING THERAPEUTIC SENSORY STIMULATION GARDEN (TSSG) AS A REHABILITATION GARDEN IN A HEALTHCARE CENTRE}

Overall, it was identified that group sessions utilized the central area, which was $\mathrm{C} 1$ and $\mathrm{C} 3$ and left the area. It was noted that spacious areas played an important role to accommodate group activity during rehabilitation in TSSG. Besides that, the safety issue was identified to be one of the main priorities in choosing the space to be used for group sessions. Wet flooring was one of the factors why GS2 was moved from L1 to L2, or L3 or C3. Compared to the group session, the space use pattern for an individual session (IS) tends to be more distributed and the whole area of TSSG was accessed by the patients. $\mathrm{C} 2$ was used the most followed by C3, R2, R3, and R4 (refer Fig. 4).

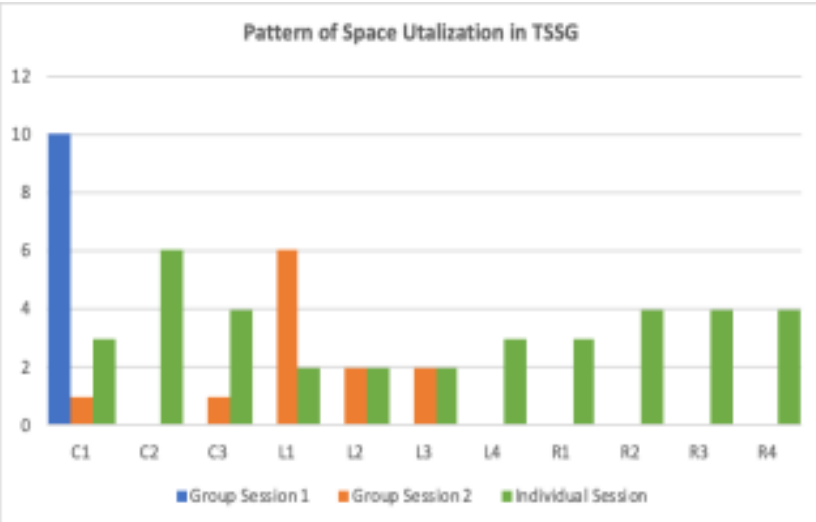

Fig. 3. Pattern of space use in TSSG.

\section{A Movement Pattern}

The pattern of patients' movement was observed and recorded accordingly to divided spaces in TSSG (refer Fig. 1 and Table I). The movement pattern was recorded starting from GS1 to GS2 to an individual session. Two types of patterns were displayed. A structured movement pattern was captured in patients' movement, from GS1 to GS2 (refer Table I). The lead therapist has seen to instruct all patients on where they need to head to after their activity in GS1 had finished. It was observed that patients moved into a group and lead by a group of therapists. There was a group of patients who propelled their wheelchair and there were also patients who were pushed by their caregivers or therapists. Although patients have no sense of control over where they wanted to go in the garden. In this session, they learned to understand and follow instructions given.

Contrary to the movement pattern seen in the group session, a scattered movement pattern was exhibited during individual sessions. This scenario was portrayed in sessions one, two and eight (refer to Table I). During these sessions, patients were observed to move in random directions. Patients needed to make an impromptu decision on what to do and where to go as it was not a preplanned activity. Patients tend to move freely around the garden and it was noted that the whole area of TSSG was fully explored. They were assisted by the therapist if their caregivers were not around.

This observational study has shown that rehabilitation during individual sessions offers a sense of control [18] to patients. They can choose and decide where they wanted to go. Nonetheless, it was also observed that there were a few patients with caregivers choose to sit down on chairs or raised planting bed and do nothing. They seem to segregate themselves from others. Therefore, this scenario suggested that rehabilitation in the garden also offers private space and time for users [7], [18].

Besides that, social interaction was also displayed between peers. Contrary to the finding by [2], patients and caregivers seem to form an interaction with staff too. However, for most of the time, only selected patients will remain in TSSG after GS2. The remaining patients continued their rehabilitation sessions with the therapist in the garden (refer Table I). As for others, either they went to their ward to rest or they continue their rehabilitation sessions indoor at level 10 or 11 . A structured movement pattern was displayed in this session as the therapist will determine the area where the patients need to be. Most of it, they will straight away go to C2 after GS2 finished except for session nine.

Table- I: Movement pattern of GS1 to GS2 to IS

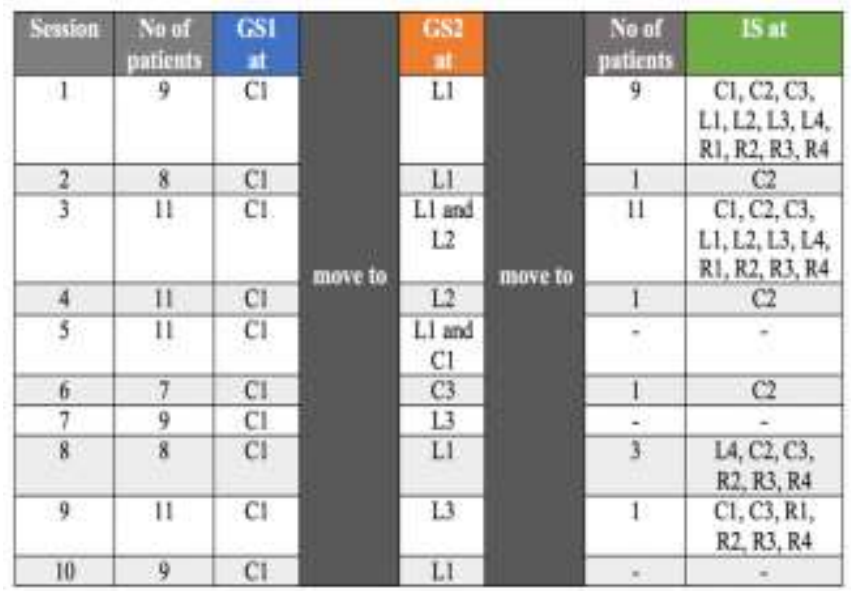

\section{B Activity Pattern}

Based on the observation, patients' activities during rehabilitation were performed in two ways; through group and individual interventions. The group intervention consists of two activities, GS1 and GS2. It was held back to back (refer Table I). GS1 activities appeared to focus more on social and mild physical intervention. The session started with singing the National Anthem, Negaraku, followed by a warming up session. Patients assisted by therapists did simple stretching exercises before playing Poison Ball game. The patients passed the ball around, and when the music stops, the person holding the ball needed to introduce themselves and shared a brief background with their peers.

This activity was observed to encourage patients to communicate with peers and boost their confidence level. Group interventions that are well organized and structured played an important role to help patients to develop their cognitive and social abilities [22]. Meanwhile, the activities carried in GS2 were observed to focus more on physical intervention, which involved rule games such as Bowling, Snake and Ladder, and Bean Bag Toss games. Based on the data collected in ten sessions, the Poison Ball game and Bowling game observed to be dominating in GS1 and GS2 (refer to Fig. 4).

Activities in individual interventions tend to be more diversified (refer to Fig. 5). The activities carried in this 
session could be classified into two types. They were categorized as free-flow activities and customized activities. In free-flow activities, patients were allowed to make their own decision on what to do and where to go. These sessions supported the sense of control element as suggested by [18] in Theory of Supportive Garden. Individual customization helps patients themselves to gain control over their chosen activities [22].

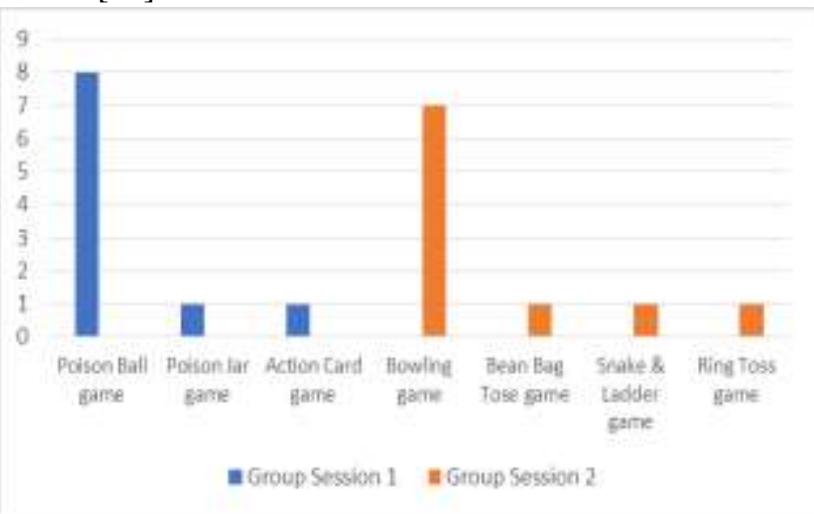

Fig. 4. Pattern of activties for GS in ten sessions.

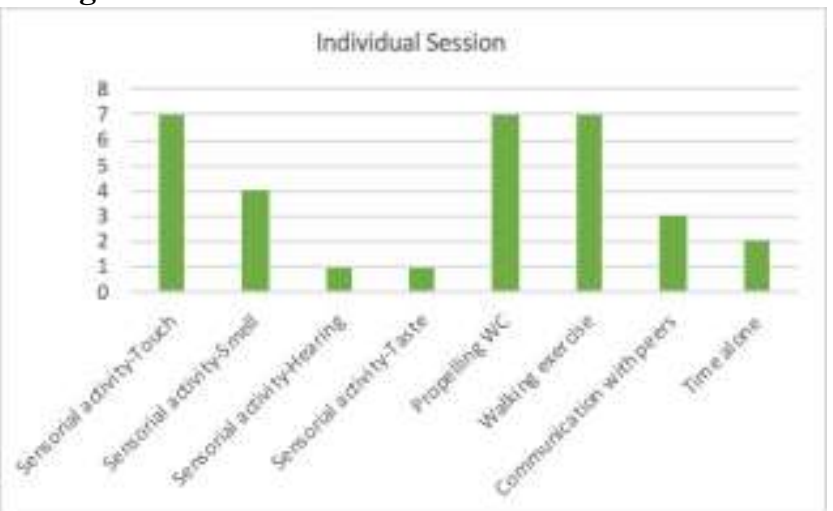

Fig. 5. Pattern of activities for individual sessions in TSSG for seven sessions.

Compared to the free-flow activity in individual sessions, the customized activities ware observed to be led by the therapists in charged. It seems that the activity was planned to suit the patient's individual needs. This finding was consistence with the suggestion made by [22], where it was suggested that the intervention activities should include a patient's self-management approach, involving meaningful activities and tailored to the individual patients. In these sessions, patients were observed to perform walking tasks using a walking stick or walking frame at the center part of $\mathrm{C} 2$ and using the route around the pergola, assisted by therapists at their side to support their balancing.

These activities helped to assist the main issues of sensorimotor impairments. Walking, strength, endurance, coordination and hand functions were associated as the main issues faced by neurology patients [22]. Apart from that, patients were also exposed to sensory stimulation activities at the center of $\mathrm{C} 2$. In this session, patients were observed to interact with elements of nature through sensory stimulation activities. For example, based on the observations done during sensory stimulation activities on session six, it was observed that the patient slowly walked bare-footed on the grass assisted by a therapist. The patient walked using his walking frame in the $\mathrm{C} 2$ area to stimulate his tactile senses. These findings were inline with [23] that sensorial intervention is an important element in the intervention for neurological disorder patients and the garden does play its roles as an outdoor intervention in supporting neurosensory intervention.

For feet stimulation, patients in TSSG were observed to walk on grass and feel the uneven surface of pebbles. These activities seem to be as the most preferable activity chosen by therapists. Grass and pebbles were used as the properties that offer tactile stimulation. Sensorial activity (touch), propelling and walking exercises identified as the most frequent activities done by patients in all seven individual sessions. However, sensorial activity (hearing and taste) appeared as the least activity is done, which appeared to be only once in seven sessions (refer to Fig. 5). It was noticeable in the third session, that the only patient that responded to hearing and taste sensorial activity was a visual and physical impaired person.

Referring to Table I, it was also identified that IS in TSSG took place only seven times out of 10 times. The outdoor intervention in TSSG seems to be focusing more on group interventions. It can be reflected through the number of sessions and the division of the intervention slots. Twothird of the interventions were dedicated to group activities; meanwhile, one-third of the session was reserved for individual activities. On top of that, only selected numbers of patients were involved in IS, except in sessions one and three. This might happen due to individual interventions that normally took place in a clinical setting or the indoor gym [1], [4], [18] the usage of TSSG was designed to focus more on group interventions. Moreover, in [22] highlighted that group interventions helped in assisting patients to develop new friendships and creating a feeling of belonging, apart from boosting patient's self-esteem and life motivation. Most of the depressed patients admitted that they had a better life since they joined rehabilitation intervention.

\section{CONCLUSION}

This study undertakes to develop an understanding of how TSSG was used for rehabilitation in the acute hospital. It has allowed a deeper insight into the needs of neurological disorder patients as the prime user during rehabilitation intervention in the garden. From this observational study, it was found that, in identifying the space use, movement and activity pattern in TSSG during rehabilitation, three main elements: people, environment and activities were involved. Therefore, understanding of these three elements was vitally important to design a garden for rehabilitation.

This study shows that TSSG appears to be beneficial as a complementary tool for rehabilitation among neurological disorder patients, especially in their early stages of intervention. However, more sensorial elements or sensorial-based activities were suggested to be used in the group interventions, as for now, the sensorial elements were used more in individual intervention. TSSG could also offer a holistic approach to empowering patients to deal with their disabilities, thus maximizing their physical, social and emotional capabilities. 


\section{UNDERSTANDING THERAPEUTIC SENSORY STIMULATION GARDEN (TSSG) AS A REHABILITATION GARDEN IN A HEALTHCARE CENTRE}

Conclusively, the finding of this study may assist future research in the field of design, people-environment relationship and rehabilitation medicine. Further research urged to be carried out to identify garden elements that supported the rehabilitation intervention session in TSSG. It is suggested that the assessment of TSSG in terms of spatial garden design and composition of characteristics is done via a standard assessment tool. Thus, the results could be used as additional recommendations for future improvement of TSSG design that served as a garden for rehabilitation.

\section{ACKNOWLEDGMENT}

Author thanks Ministry of Education Malaysia (Higher Learning) and Universiti Sains Malaysia for sponsor and financial support. Appreciation also goes to the Center for Sustainable Urban Planning and Real Estate, Faculty of Built Environment, University of Malaya (SUPRE) and Rehabilitation Department, University of Malaya Medical Center (UMMC) for the invaluable support during the research period.

\section{REFERENCES}

1. Amat, N. S. A., and Shukor, S. F. A. "Comparison of exercise in a green outdoor environment versus indoor activities among cardiac survivors," Alam Cipta, vol. 8(2), 2015, pp. 41-43.

2. Blennerhassett, J. M., Borschmann, K. N., Lipson-Smith, R. A., and Bernhardt, J. "Behavioral mapping of patient activity to explore the built environment during rehabilitation." HERD: Health Environments Research and Design Journal, 11(3), 2018, pp. 109-123.

3. Killington, M., Fyfe, D., Patching, A., Habib, P., McNamara, A., Kay, R., Kochiyil, V., and Crotty, M. "Rehabilitation environments: Service users' perspective." Health Expectations, 22(3), 2019, pp. 396404.

4. Sandal, L. F., Thorlund, J. B., Ulrich, R. S., Dieppe, P. A., and Roos, E. M. "Exploring the effect of space and place on response to exercise therapy for knee and hip pain-A protocol for a double-blind randomised controlled clinical trial: The CONEX trial," BMJ Open, vol. 5(3), 2015, pp. 1-11.

5. Hussein, H., and Daud, M. N. "Examining the methods for investigating behavioral clues of special-schooled children." Field Methods, 27(1), 2015, pp. 97-112.

6. World Health Organization (WHO), Neurological disorders: Public health challenge. Geneva: WHO Press, 2006.

7. Winterbottom, D. and Wagenfeld, A. Design for healing spaces: Therapeutic gardens. Oregon: Timber Press, 2015.

8. Abd Shukor, S. F., Amat, N. S. A., Maulan, S., and Yatim, S. M. "The use of green outdoor environments for cardiac survivors' rehabilitation therapy." Bridging the Gap: ECLAS Conference Proceedings, 2016, pp. 351353.

9. Davis, B. E. "Rooftop hospital gardens for physical therapy: A post-occupancy evaluation." HERD: Health Environments Research and Design Journal, vol. 4(3), 2011, pp. 14-43.

10. Ibrahim, F., Harun, W.M.W., Samad, M.H.A. and Kamaruddin, W.N. W. S. W. "The Physical Attributes of Healing Garden for A Century Old Healthcare Premises." International Transaction Journal of Engineering, Management, \& Applied Sciences \& Technologies, 6(2), 2015, pp. 47-59.
11. Adnan, S. N. F., and Shukor, S. F. A. "The application of the Common Design Recommendations (CDR) in assessing restorative green outdoor environment," Alam Cipta, vol. 8(2), 2015, pp. 63-71.

12. Badan Amal dan Kebajikan Tenaga Isteri-isteri (BAKTI), Therapeutic sensory stimulation garden: An introduction by BAKTI-MIND project, Kuala Lumpur: BAKTI, 2017.

13. Hussein, H., Omar, Z., and Ishak, S. A. "Sensory garden for an inclusive society," Asian Journal of Behavioural Studies, vol. 1(4), 2016, pp. 33-43.

14. Abd Shukor, S. F., Amat, N. S. A., Maulan, S., and Yatim, S. M. "The use of green outdoor environments for cardiac survivors' rehabilitation therapy," Bridging the Gap. ECLAS Conference 2016, Rapperswil, Switzerland. Conference Proceedings. Series of the Institute for Landscape and Open Space, pp. 351-353.

15. Djukanović, Z., Marić, J. and Giofrè. F. "Evaluation of hospital outdoor spaces through users'participation analysis." Facta Universitatis, Series: Architecture and Civil Engineering, 2017, pp. 73-084.

16. Spring, J. A. "Design of evidence-based gardens and garden therapy for neurodisability in Scandinavia: Data from 14 sites." Neurodegenerative disease management 6(2), 2016, pp. 87-98.

17. Sandal, L. F., Thorlund, J. B., Ulrich, R. S., Dieppe, P. A., and Roos, E. M. "Exploring the effect of space and place on response to exercise therapy for knee and hip pain-A protocol for a double-blind randomised controlled clinical trial: The CONEX trial," BMJ Open, vol. 5(3), 2015, pp. 1-11.

18. Ulrich, R. S. "Chapter 2: Effects of gardens on health outcomes: Theory and research." Healing Gardens: Therapeutic Benefits and Design Recommendations. Marcus, C.C. and Barnes, M. New York: John Wiley and Sons, 1999

19. "rehabilitation." Farlex Partner Medical Dictionary. [Online]. Available: https://medicaldictionary.thefreedictionary.com/rehabilitation

20. Idris, M. M., Sibley, M., and Hadjri, K. "Investigating space use patterns in a Malaysian hospital courtyard garden: Lessons from real-time observation of patients, staff and visitors," Environment-Behaviour Proceedings Journal, vol. 3(8), 2018, pp. 32-45.

21. Thompson, C. W. "Activity, exercise and the planning and design of outdoor spaces." Journal of Environmental Psychology, 34, 2013, pp. 79-96.

22. Pallesen, H., Aadal, L., Moe, S., and Arntzen, C "Gateway to recovery: A comparative analysis of stroke patients' experiences of change and learning in Norway and Denmark." Rehabilitation Research and Practice, 2019, pp. 1-14.

23. Attwell, C., Jöhr, J., Pincherle, A., Pignat, J. M., Kaufmann, N., Knebel, J. F., Berney, L., Ryvlin, P., and Diserens, K. "Neurosensory stimulation outdoors enhances cognition recovery in cognitive motor dissociation: A prospective crossover study." NeuroRehabilitation, 2019, pp. 1-10 


\section{AUTHORS PROFILE}

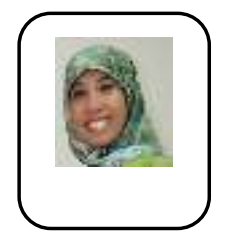

Noor Azlina Mohamed Khalid is currently a Ph.D. student in Faculty of Built Environment, University Malaya, Kuala Lumpur. She is a lecturer in Product Design Department, School of The Arts, University Sains Malaysia, Pulau Pinang. She completed her Master of Design in Industrial Design from Swinburne University in Melbourne, Australia. Her research interests are on Universal Design, Design for Health, User-Centered Design, Design Collaboration (Co-design), Environment-Behaviour interactions, and Transdisciplinary Design.

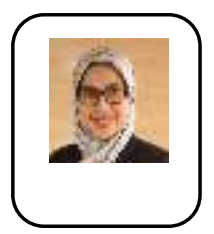

Lydia Abdul Latif is a Professor and Consultant in the Department of Rehabilitation Medicine. She has completed her Fellowship training in Neuromodulation in the Department of Physical Medicine and Rehabilitation, Spaulding Rehabilitation Hospital, Harvard Medical School. She is the pioneer in this field in Malaysia. She used non-invasive brain stimulation to improve recovery for stroke survivors. She has published work in Tier 1, WOS journal and invited to present papers both local and abroad. She holds several positions both local and international as Executive committee for Malaysian Association of Rehabilitation Physician and International Society of Physical and Rehabilitation Medicine and has strong international connections.

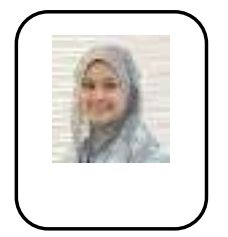

Hazreena Hussein has 20 years of progressive teaching and research experience at the University of Malaya. Currently, she is an Associate Professor at the Faculty of Built Environment. Her research interests are on Environment-Behaviour interactions, inclusive access to outdoor environments, and Multisensory stimulation environments. She has been the Principal Investigator for some projects: 'Landscape identity of Cameron Highlands Hill Station: Soundscape' (2013-2017) and 'Enhancing wellbeing through recreational and sensory therapy in landscape design ' (2014-2017). Hazreena has been granted seed money from the Swiss Federal Institute of Technology Zurich (ETH) on 'The physiological responses to Therapeutic Sensory Stimulation Garden: A pilot study (2016-2017). Since 2012, she serves as the Editorial Board of Asian Journal of Environment-Behaviour Studies and Journal of Asian Behavioural Studies. 